\title{
Dietary patterns and oesophageal squamous cell carcinoma: a systematic review and meta-analysis
}

\author{
X Liu ${ }^{1}, X$ Wang ${ }^{\star, 1}, \mathrm{~S} \mathrm{Lin}{ }^{1}, \mathrm{~J} \mathrm{Yuan}^{1}$ and I T-S Yu ${ }^{1}$ \\ ${ }^{1}$ Division of Occupational and Environmental Health, JC School of Public Health and Primary Care, The Chinese University of \\ Hong Kong, 4/F School of Public Health, Prince of Wales Hospital, Shatin, N.T., Hong Kong, SAR, China
}

Background/Objective: Dietary patterns, which represent a complex integration of food and nutrients, have been used to explore the association between dietary factors and the risk of oesophageal cancer. However, the association remains unclear. This systematic review was performed to evaluate the relationship between dietary patterns and oesophageal squamous cell carcinoma (ESCC) by pooling available data from existing studies.

Methods: Pertinent articles published up to the end of 2013 were systematically searched and retrieved. The most common dietary patterns with high loadings of foods/nutrients were selected. Adjusted odds ratios (ORs) were derived by comparing the highest with the lowest categories of dietary pattern scores and by using a random-effect model. Heterogeneity was tested using $l^{2}$ statistic.

Results: From nine available case-control studies, in which smoking and other confounding factors were considered, three most common dietary patterns were selected: western pattern, healthy pattern, and drinker/alcohol pattern. Healthy pattern was significantly associated with a decreased risk of $\operatorname{ESCC~}(\mathrm{OR}=0.36,95 \%$ confidence interval $(\mathrm{Cl})$ : $0.23,0.49)$; drinker/alcohol pattern was related to a significantly increased risk $(\mathrm{OR}=2.34,95 \% \mathrm{Cl}: 1.22,3.45)$, while no significant association with western pattern was observed $(\mathrm{OR}=1.29,95 \% \mathrm{Cl}: 0.83,1.75)$.

Conclusions: Based on available studies, though limited in number, this meta-analysis suggests that some dietary patterns may be associated with the risk of ESCC.

Oesophageal cancer was the eighth most common cancer and the sixth most common cause of death from cancer worldwide (Jemal et al, 2011). There are two major histologic types of oesophageal cancer: oesophageal squamous cell carcinoma (ESCC) and oesophageal adenocarcinoma (EAC). Oesophageal squamous cell carcinoma accounts for $90 \%$ of oesophageal cancer cases (Jemal et al, 2011). Therefore, this systematic review focused on ESCC.

Some risk factors, such as family cancer history, genetic factors, are difficult to modify (Dong et al, 2008; Wu et al, 2011), but epidemiological studies have suggested that healthy diet/lifestyle is critical for the prevention of oesophageal cancer (American
Institute for Cancer Research and World Cancer Research Fund, 2007; Palladino-Davis et al, 2013). Increasing evidence is highlighting the crucial role of dietary components in inducing or modifying carcinogenic process (Reszka et al, 2006). Some researchers suggested that, for ESCC, nearly $30 \%$ of population attributable risk (PAR) were due to low consumption of fruits and vegetables (Engel et al, 2003), and up to nearly $90 \%$ of PAR were attributed to a combination of smoking, alcohol consumption, and low fruit and vegetable consumption (Engel et al, 2003). In contrast, for EAC, dietary factors, such as low intake of fruits and vegetables, only accounted for about $15 \%$ of PAR (Engel et al, 2003).

*Correspondence: Professor X Wang; E-mail: xrwang@cuhk.edu.hk

Received 1 December 2013; revised 28 February 2014; accepted 8 March 2014; published online 8 April 2014

(c) 2014 Cancer Research UK. All rights reserved 0007-0920/14 
On the other hand, most randomised controlled trials failed to confirm protective roles of single or combined dietary elements in cancer prevention, and they provided mixed results on micronutrients (Li et al, 1993; Rao et al, 1994; Wright et al, 2007; Qiao et al, 2009). This may be understandable, because foods and nutrients are never eaten in isolation, and their effects are likely to be interacted (Erickson, 2002; Hu, 2002). The complicate interaction of dietary components has promoted the adoption of comprehensive methods to derive dietary patterns. Some priori techniques related to dietary index were adopted to describe dietary patterns (Bosetti et al, 2003; Jessri et al, 2011), but these techniques based on the previous knowledge may not reflect the current status (Reedy et al, 2010). The dietary patterns derived from the posteriori method, such as cluster analysis, factor analysis, and principal component analysis, aggregate variables into the factors representing broad eating patterns of specific population (Reedy et al, 2010).

A previous review performed a qualitative analysis on the relationship between upper aero-digestive cancers (including oesophageal cancer) and dietary patterns (Bravi et al, 2012a). However, a pooled estimate of the size effect has not been done yet. Hence, this systematic review with meta-analysis was conducted, aiming at evaluating the association between dietary patterns and the risk of ESCC.

\section{MATERIALS AND METHODS}

Search strategy and selection criteria. Criteria (Stroup et al, 2000) for conducting and reporting meta-analysis of observational studies were followed. A systematic search for articles up to the end of 2013 was conducted through four databases: PubMed, Embase, Chinese National Knowledge Infrastructure (CNKI, http://www.cnki.net), and VIP Journal integration platform (VJIP, http://en.cqvip.com). Key words used for the literature search included 'oesophageal cancer', 'oesophageal squamous cell carcinoma', 'oesophageal neoplasm', 'dietary pattern', 'nutrient pattern', 'food pattern', 'eating pattern', 'dietary habits', 'diet', 'dietary', and 'nutrients'. More details of the search strategy were presented in Appendix 1. Backward and forward citation tracking, in both ISI Web of Science and Scopus, were also used to identify articles.

Two reviewers (Liu and Lin) independently conducted the literature search, identified potential studies, and extracted detailed information from included articles. Discrepancies were resolved through the group discussion with the third reviewer (Wang). Inclusion criteria were cohort, case-control, or randomised controlled trial studies, which restricted to human studies and published in either English or Chinese, and to studies using posterior methods (factor analysis or principle component factor analysis or cluster analysis). Cross-sectional studies, animal studies, non-original research (reviews, editorials, or comments), abstracts, unpublished studies, and duplicated studies were excluded. Exposure variable of interest was any type of dietary patterns, and outcome variable was incident cases of ESCC. The risk estimates with corresponding 95\% confidence intervals (95\% CIs) were reported. In the end, nine eligible articles (case-control design) (Bahmanyar and Ye, 2006; De Stefani et al, 2008a, b, 2009; Hajizadeh et al, 2010, 2012; Navarro Silvera et al, 2011; Ibiebele et al, 2012; Bravi et al, 2012b) containing 1464 cases and 7863 controls were identified through a full text examination of 265 potential publications. Figure 1 shows a flow chart of literature search. Three articles (De Stefani et al, 2008a, b, 2009) came from a study in Uruguay and two articles (Hajizadeh et al, 2010, 2012) from a study in Iran were treated as five different studies, because the articles from a same study reported different dietary patterns: the three articles from the Uruguay study reported three nutrient patterns (high fat, carbohydrates, and antioxidants) in men and women (De Stefani et al, 2008a), four food patterns (traditional, healthy, high fat, and drinker) in men and women (De Stefani et al, 2008b), and four food patterns (prudent, traditional, western, and drinker) in men (De Stefani et al, 2009), respectively; the two articles from the Iran study reported two nutrient patterns (factor 1 and factor 2) (Hajizadeh et al, 2012) and two food patterns (healthy diet and western diet) (Hajizadeh et al, 2010), respectively.

Three most common dietary patterns were selected from the included articles. The dietary patterns in these articles had similar factor loading of principle components. The first pattern, named as healthy pattern, had a higher loading of fruits, fresh vegetables, dietary fibre, and antioxidants (such as plant sterols, vitamin C, vitamin E, carotenoids, and flavonoids), and lower in fat dairy, processed food and red meat. The articles under consideration labelled it as 'fruits and vegetables' (Navarro Silvera et al, 2011; Ibiebele et al, 2012), 'healthy' (Bahmanyar and Ye, 2006; De Stefani et al, 2008b; Hajizadeh et al, 2010), 'antioxidants' (De Stefani et al, 2008a), 'factor 2' (Hajizadeh et al, 2012), 'vitamins and fibre' (Bravi et al, 2012b), and 'prudent' (De Stefani et al, 2009). The second pattern was named as western pattern, which had higher loading of fat, red meat, processed food and fat acid, and lower loading of fruits, vegetables, and dietary fibres. The examined articles labelled it as 'meat and fat' (Ibiebele et al, 2012), 'high fat' (De Stefani et al, 2008a, b), 'western' (Bahmanyar and Ye, 2006; De Stefani et al, 2009; Hajizadeh et al, 2010), 'factor1' (Hajizadeh et al, 2012), 'meat/nitrite' (Navarro Silvera et al, 2011), and 'animal products

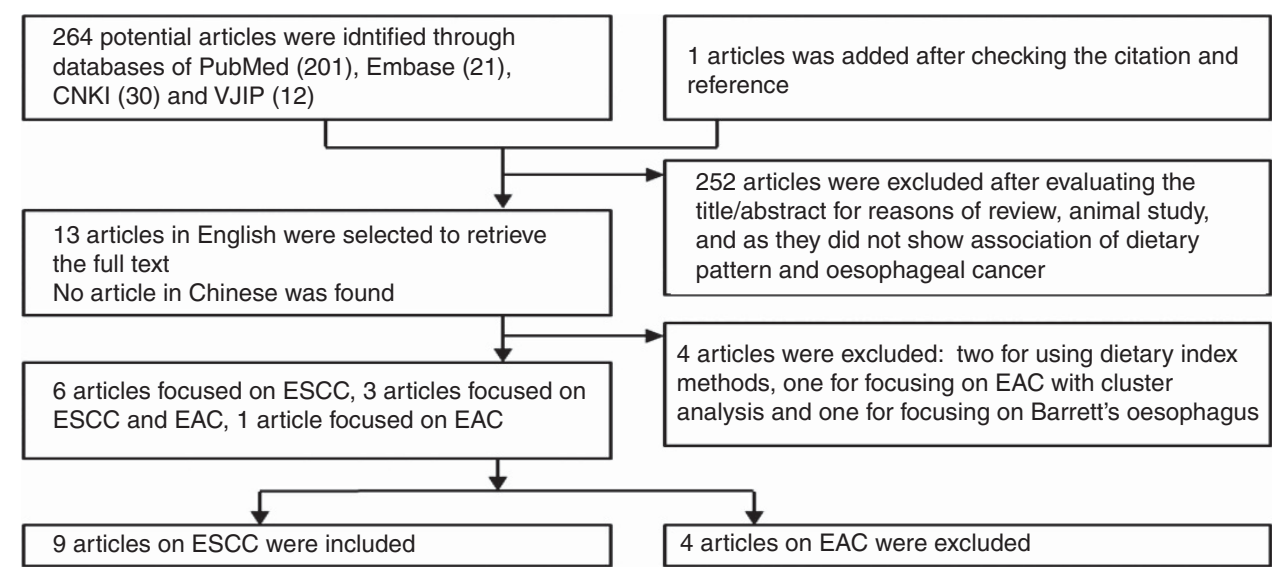

ESCC: oesophageal squamous cell carcinoma; EAC: oesophageal adenocarcinoma

Figure 1. Flow chart of systematic review on dietary pattern and oesophageal squamous cell carcinoma. 
and related multiple components' (Bravi et al, 2012b). The third pattern, named as drinker/alcohol pattern, had higher loading of wines, beers, and spirits. The examined studies labelled it as 'drinker' (De Stefani et al, 2008b, 2009), 'alcohol drinker' (Bahmanyar and Ye, 2006), and 'smoking/alcohol' (Navarro Silvera et al, 2011).

Data extraction. Information was extracted from the included studies, including the first author, year of publication, country, study design, sample size, dietary assessment method, dietary patterns derived method, dietary patterns identified, adjusted odds ratios (adjusted ORs) with 95\% CI, adjusted variables and other considered covariates (Appendix 2).

Quality of the included articles was assessed according to the Newcastle-Ottawa Criteria for the non-randomised studies (Wells et al, 2011). A maximum of 9 points was assigned to each study: 4 for selection, 2 for comparability, and 3 for assessment of outcomes or exposures. Each study was classified as low (0-3), moderate (4-6), and high quality (7-9) in terms of the total scores.

Statistical analysis. Meta-analysis was conducted to evaluate the pooled effects, based on adjusted ORs and 95\% CI, by comparing the highest with the lowest categories of dietary pattern scores in each of three selected patterns. Cutoff points of the different categories in each article was identified: tertile method was used in three articles (Bahmanyar and Ye, 2006; De Stefani et al, 2008b, 2009), quartile method in four articles (De Stefani et al, 2008a; Navarro Silvera et al, 2011; Ibiebele et al, 2012; Bravi et al, 2012b), and dichotomy (median value) in two articles (Hajizadeh et al, 2010, 2012). Dersimonian and Laird random-effect model was adopted to derive pooled results and forest plot was used to visibly describe the magnitude of the effects (Petitti, 2000). Heterogeneity was examined with $I^{2}$ statistic (Higgins and Green, 2011), and publication bias was assessed by funnel plot together with Egger's tests (Sterne and Egger, 2001). Subgroup analyses were conducted according to pattern type (nutrient pattern or food pattern). Finally, sensitivity analysis was conducted by excluding the outliers and non-Asian articles. Statistical analysis was carried out with Stata statistical software (version 12.0; Stata Corporation, College Station, TX, USA).

\section{RESULTS}

Characteristics of included studies. All of nine included articles had higher methodological quality with total score ranging from 7 to 8 (the detail information is presented in Appendix 3). In nine included articles, food frequency questionnaire (FFQ) was used to collect dietary information and principle component factor analysis was adopted to derive dietary patterns. Although the confounding factors and their categorisations were not same in the nine articles, the effect size in each article was adjusted with major potential confounding variables, including age, sex, body mass index (BMI), and education. Eight articles took smoking status as a confounding factor and one article (Navarro Silvera et al, 2011) took it as a component. Five articles from western countries (Bahmanyar and Ye, 2006; De Stefani et al, 2008b, 2009; Navarro Silvera et al, 2011; Ibiebele et al, 2012) took alcohol drinking as a component when exploring dietary patterns, and the other two articles (De Stefani et al, 2008a; Bravi et al, 2012b) in western countries took alcohol drinking as a confounding factor, the last two articles from Iran (Hajizadeh et al, 2010, 2012) did not take alcohol drinking as a component or as a confounding factor. Seven articles were conducted in non-Asian countries: one in Australia (Ibiebele et al, 2012), Sweden (Bahmanyar and Ye, 2006), USA (Navarro Silvera et al, 2011) and Italy (Bravi et al, 2012b), respectively, and three (De Stefani et al, 2008a, b, 2009) in Uruguay, and two (Hajizadeh et al, 2010, 2012) in an Asian country (Iran). Thirty-five percent of cases in Ibiebele's report (Ibiebele et al, 2012) and all cases in other eight articles were newly diagnosed patients with pathological confirmation. Three articles (Bahmanyar and Ye, 2006; Navarro Silvera et al, 2011; Ibiebele et al, 2012) recruited population-based controls that were randomly selected from general population of the study areas, and other six articles (De Stefani et al, 2008a, b, 2009; Hajizadeh et al, 2010, 2012; Bravi et al, 2012b) recruited hospital-based controls living in the same geographic areas and admitted to the same hospital for a wide spectrum of non-neoplastic diseases, unrelated to tobacco smoking, alcohol drinking, or long-term modifications of diet. The controls and cases in eight articles included both men and women, but one article (De Stefani et al, 2009) recruited only men cases and controls. Both cases and controls aged up to 89 years old. The participants in nine articles were asked to recall food exposure information at least 1 year (ranged from 1 to 20 years) before being diagnosed as ESCC (for cases) or being interviewed (for controls). However, referring to the interval between patients being diagnosed as ESCC and the administration of FFQ, only one article (Bravi et al, 2012b) described that over $85 \%$ of cases were interviewed within 3 months since diagnosis and two articles (De Stefani et al, 2008a, b) described the FFQ was conducted shortly after patients' admission, six articles (Bahmanyar and Ye, 2006; De Stefani et al, 2009; Hajizadeh et al, 2010, 2012; Navarro Silvera et al, 2011; Ibiebele et al, 2012) did not describe. Eight articles (except one, Navarro Silvera et al, 2011) assessed the reproducibility of FFQ and five articles (Hajizadeh et al, 2010, 2012; Navarro Silvera et al, 2011; Ibiebele et al, 2012; Bravi et al, 2012b) examined the validity of FFQ. All of the nine articles identified western pattern and healthy pattern, while four articles (Bahmanyar and Ye, 2006; De Stefani et al, 2008b, 2009; Navarro Silvera et al, 2011) identified drinker/ alcohol pattern. Six articles focused on food patterns (Bahmanyar and Ye, 2006; De Stefani et al, 2008b, 2009; Hajizadeh et al, 2010; Navarro Silvera et al, 2011; Ibiebele et al, 2012) and other three on nutrient patterns (De Stefani et al, 2008a; Hajizadeh et al, 2012; Bravi et al, 2012b). More detailed information is given in Appendix 2.

Western pattern. When data from nine articles were pooled (Figure 2), there was an insignificantly increased risk for ESCC associated with western pattern $(\mathrm{OR}=1.29 ; 95 \% \mathrm{CI}$ : $0.83,1.75)$. The heterogeneity $\left(I^{2}=51.60 \%\right)$ was moderate. Similar results were observed in the subgroup analysis by nutrient pattern and food pattern, with substantial heterogeneity in both subgroups (Table 1).

Healthy pattern. There was a significant decrease in the risk of ESCC $(\mathrm{OR}=0.36 ; 95 \%$ CI: $0.23,0.49)$, but the heterogeneity $\left(I^{2}=67.30 \%\right)$ was moderate (Figure 3 ). Similar results were found in both nutrient pattern and food pattern in the subgroup analysis (Table 1), with apparently lower heterogeneity in food pattern $\left(I^{2}=34.9 \%\right)$.

Drinker/alcohol pattern. Pooled results from four papers showed that the drinker/alcohol pattern was significantly associated with an increased risk of ESCC $(\mathrm{OR}=2.34 ; 95 \% \mathrm{CI}: 1.22,3.45)$, and heterogeneity was lower $\left(I^{2}=48.70 \%\right)$ (Figure 4 ).

Publication bias. Funnel plot did not reveal asymmetry (Figure 5). The corresponding statistical tests did not show publication bias for healthy pattern (Egger's test, $P=0.071$ ), western pattern (Egger's test, $P=0.853$ ), and drinker/alcohol pattern (Egger's test, $P=0.093$ ).

Sensitivity analysis. There were not much changes found in the risk estimates after we excluded outlier (Hajizadeh et al, 2010) in western pattern (OR=1.28, 95\% CI: $\left.0.82,1.74, I^{2}=54.90 \%\right)$ and outlier (Navarro Silvera et al, 2011) in drinker/alcohol pattern $\left(\mathrm{OR}=2.02,95 \% \mathrm{CI}: 1.39,2.84, I^{2}=0.10 \%\right)$. Similarly, not much 


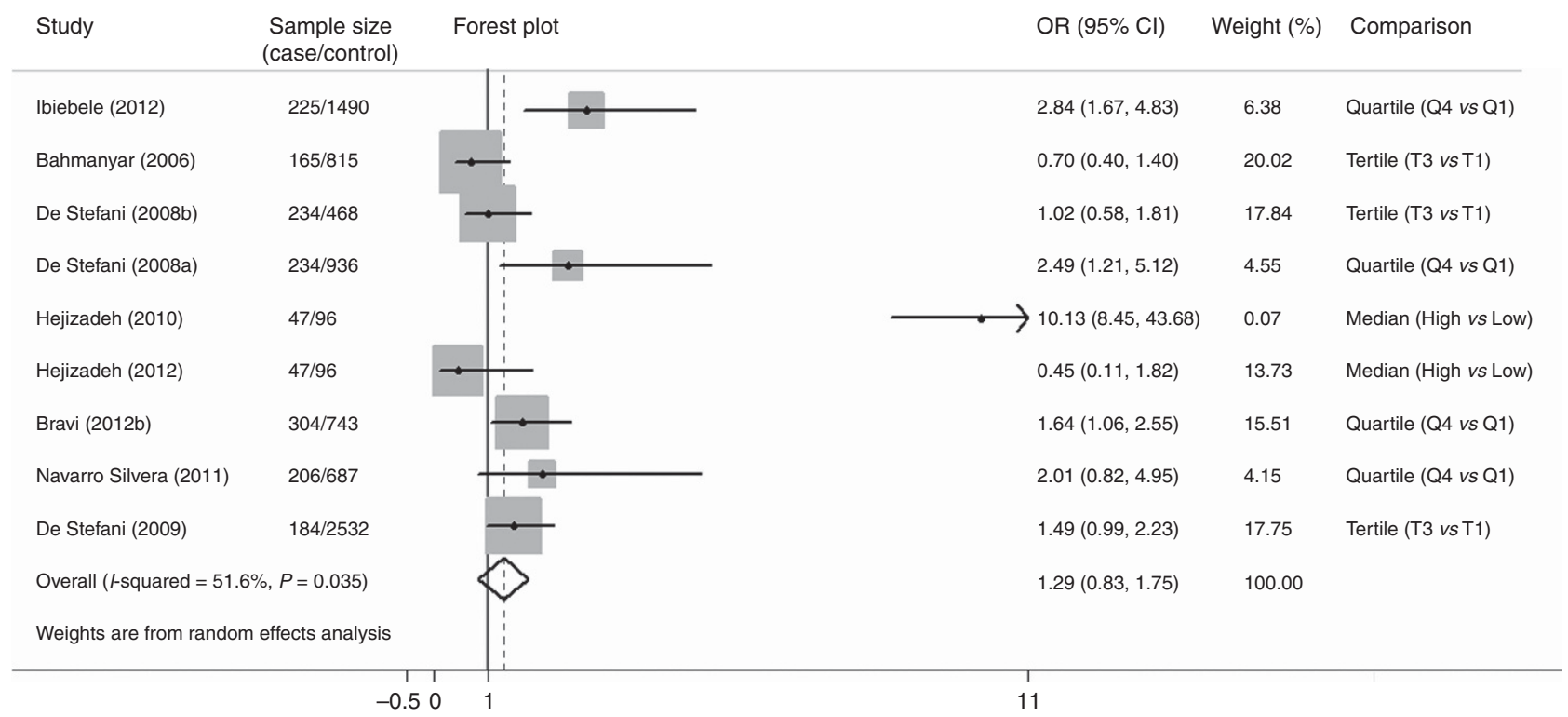

Figure 2. Forest plot of western pattern and oesophageal squamous cell carcinoma risk (the highest compared with the lowest categories).

\begin{tabular}{|c|c|c|c|c|}
\hline & $N^{a}$ & Pooled OR ${ }^{b}$ & $95 \% \mathrm{Cl}$ & $I^{2}$ statistic (\%) \\
\hline \multicolumn{5}{|l|}{ Western pattern } \\
\hline All pooled & 9 & 1.29 & $0.83,1.75$ & 51.60 \\
\hline \multicolumn{5}{|l|}{ Pattern type } \\
\hline $\begin{array}{l}\text { Nutrients pattern } \\
\text { Food pattern }\end{array}$ & $\begin{array}{l}3 \\
6\end{array}$ & $\begin{array}{l}1.33 \\
1.30\end{array}$ & $\begin{array}{l}0.28,2.38 \\
0.73,1.86\end{array}$ & $\begin{array}{l}66.40 \\
52.20\end{array}$ \\
\hline \multicolumn{5}{|l|}{ Healthy pattern } \\
\hline All pooled & 9 & 0.36 & $0.23,0.49$ & 67.30 \\
\hline \multicolumn{5}{|l|}{ Pattern type } \\
\hline $\begin{array}{l}\text { Nutrients pattern } \\
\text { Food pattern }\end{array}$ & $\begin{array}{l}3 \\
6\end{array}$ & $\begin{array}{l}0.30 \\
0.38\end{array}$ & $\begin{array}{l}0.02,0.59 \\
0.25,0.51\end{array}$ & $\begin{array}{l}85.25 \\
34.90\end{array}$ \\
\hline \multicolumn{5}{|l|}{ Alcohol pattern } \\
\hline All pooled & 4 & 2.34 & $1.22,3.45$ & 48.70 \\
\hline \multicolumn{5}{|c|}{ 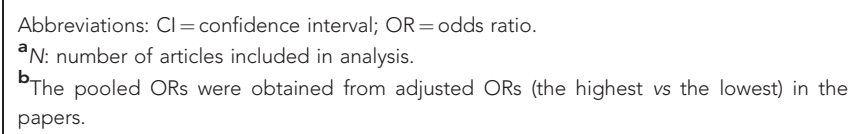 } \\
\hline
\end{tabular}

change was seen in the estimates after we excluded two articles from Asia (Hajizadeh et al, 2010, 2012) in healthy pattern $\left(\mathrm{OR}=0.40,95 \% \mathrm{CI}: 0.30,0.51, I^{2}=26.0 \%\right)$ and in western pattern $\left(\mathrm{OR}=1.40,95 \%\right.$ CI: $\left.0.92,1.89, I^{2}=52.90 \%\right)$.

\section{DISCUSSION}

Systematic review with meta-analysis on the association between dietary patterns and risk of disease have been conducted with different forms of neoplasm (Brennan et al, 2010; Magalhaes et al, 2012; Yusof et al, 2012; Bertuccio et al, 2013). However, to our best knowledge, there has been no systematic review containing a quantitative analysis to evaluate the association between dietary patterns and oesophageal cancer. The results from this meta-analysis showed that healthy pattern was significantly related to a decreased risk of ESCC, and the drinker/alcohol pattern to an increased risk.

In this systematic review, three most commonly identified dietary patterns were selected from the included articles, and each of the patterns had a similar higher factor loading. Other patterns, such as pasta and pizza pattern, carbohydrate pattern, legume/meat alternate pattern (De Stefani et al, 2008a; Navarro Silvera et al, 2011; Ibiebele et al, 2012), might also have some roles in the development of ESCC, but each of these patterns was exclusively reported in one or another article, based on which we were not able to assess these patterns.

The healthy pattern defined in this systematic review referred to a higher loading of fruits, fresh vegetables, dietary fibre and antioxidants and a lower loading of fat dairy, processed food and meat. Fruits, fresh vegetables, dietary fibre, and antioxidants were found to have critical roles in reducing the risk of oesophageal cancer (Terry et al, 2000; Freedman et al, 2007; Liu et al, 2013). This pooled result suggested that healthy pattern had a protective effect against ESCC, which was consistent with results found in all of the nine included articles. This can be explained by intake of a large amount of potential anticarcinogenic agents that were found in these food sources, including plant sterols, vitamin C, vitamin E, carotenoids, flavonoids, dietary fibre, allium compounds, glucosinolates, selenium, protease inhibitors, and limonene (Steinmetz and Potter, 1991). These factors were found to have both complementary and overlapping mechanisms of action, including the induction of detoxification enzymes, inhibition of nitrosamine formation, provision of substrate for formation of antineoplastic agents, dilution and binding of carcinogens in the digestive tract, alteration in hormone metabolism, antioxidant effects and others (Steinmetz and Potter, 1991).

The pooled results also showed that the drinker/alcohol pattern was significantly associated with an increased risk of ESCC, although the data were derived from only four papers (Bahmanyar and Ye, 2006; De Stefani et al, 2008b, 2009; Navarro Silvera et al, 2011). The result was not surprising because many previous studies reported that alcohol drinking was significantly associated with increased risk of ESCC (Islami et al, 2011; Oze et al, 2011; Bagnardi et al, 2013) and of EAC (American Institute for Cancer Research and World Cancer Research Fund, 2007). Ethanol in alcohol (including wine, beer, and liquor) is oxidised by alcohol 


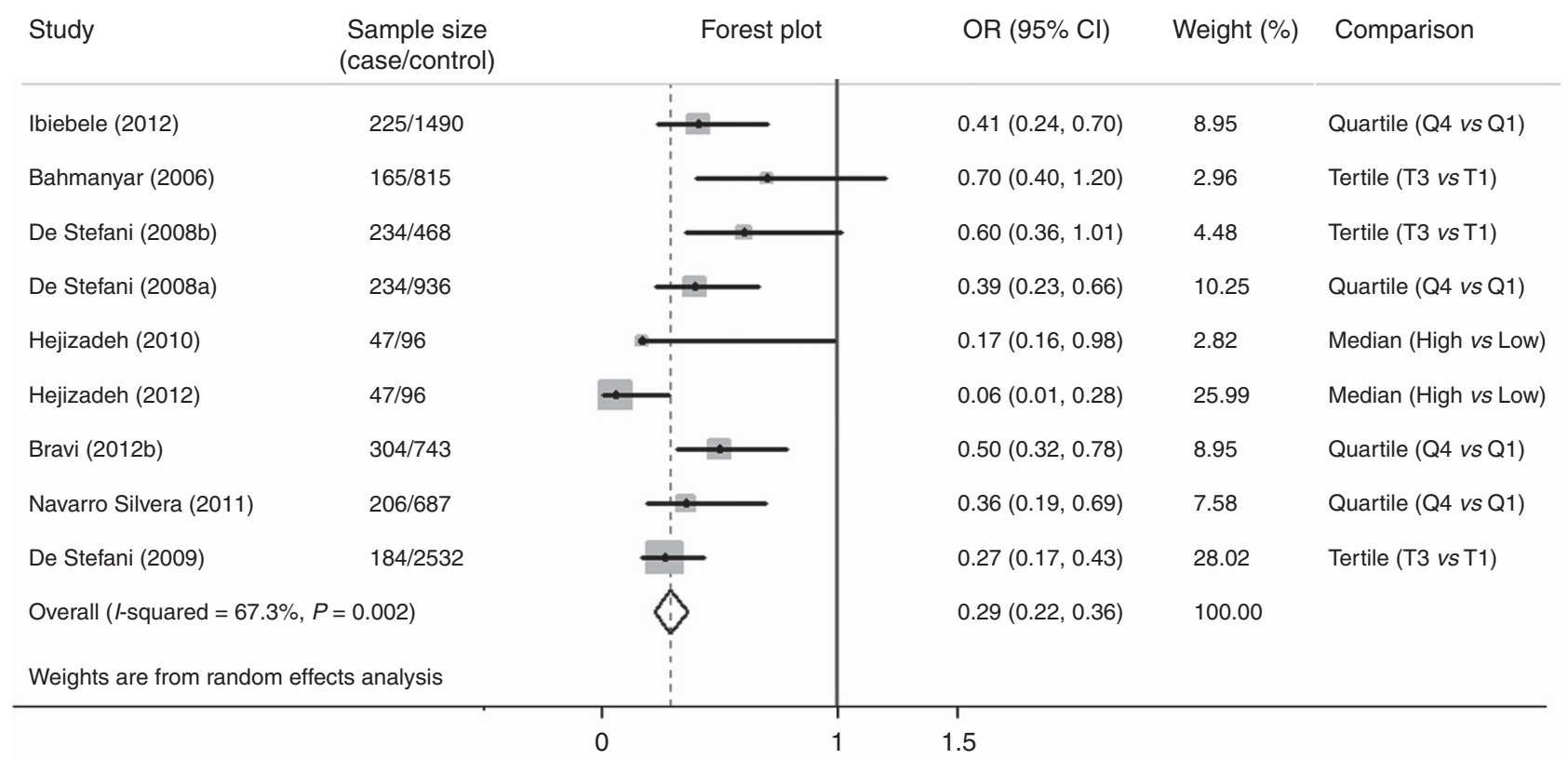

Figure 3. Forest plot of healthy pattern and oesophageal squamous cell carcinoma risk (the highest compared with the lowest categories).

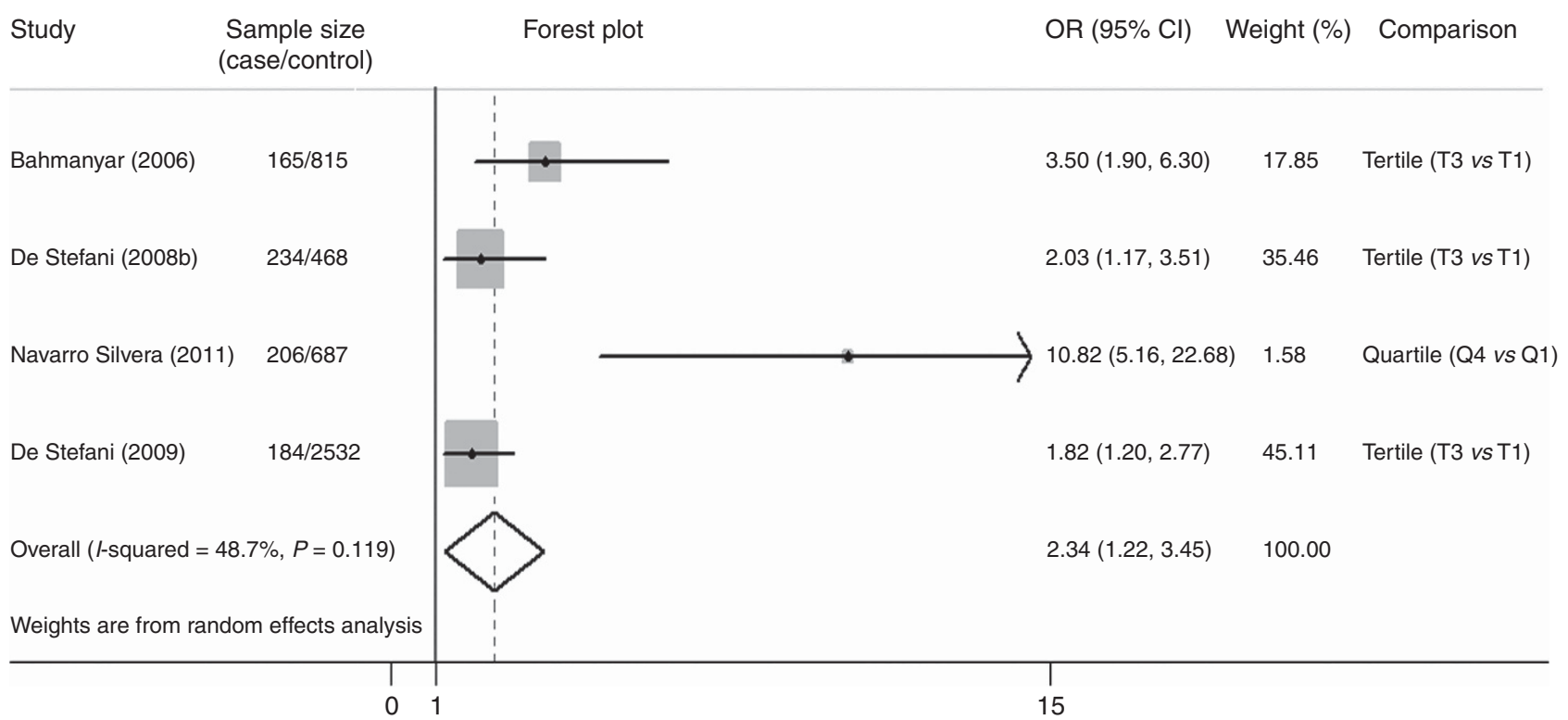

Figure 4. Forest plot of drinker/alcohol pattern and oesophageal squamous cell carcinoma risk (the highest compared with the lowest categories).
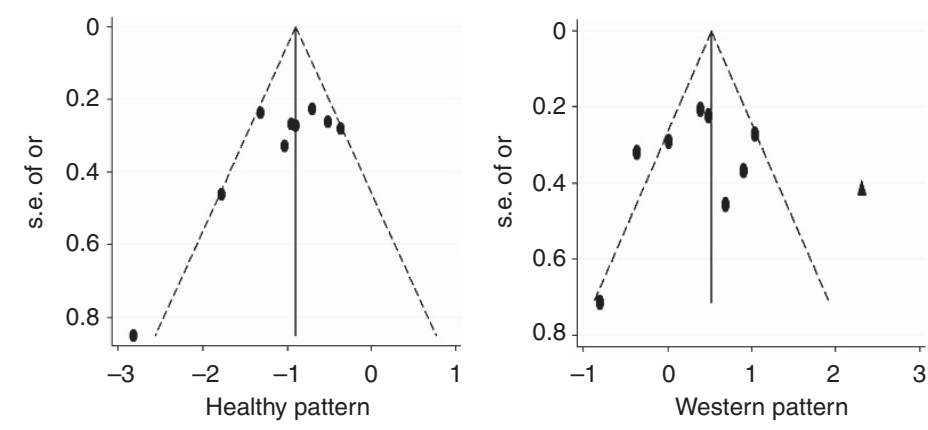

$\Delta$ Hajizadeh (2010) • Others

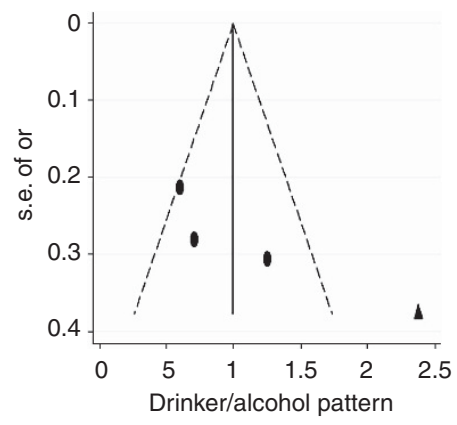

$\Delta$ Navarro Silvera (2011) • Others

Figure 5. Funnel plot with pseudo $95 \%$ confidence limits. 
dehydrogenase, which results in the generation of acetaldehyde (Seitz and Stickel, 2007). Acetaldehyde is the most toxic ethanol metabolite in alcohol-associated carcinogenesis (including carcinogenesis in oesophagus). In addition, ethanol itself stimulates carcinogenesis by inhibiting DNA methylation and by interacting with retinoid metabolism (Toh et al, 2010).

The western pattern referred to a higher loading of fat, animal food and processed food, and a lower loading of fruits, vegetables, and dietary fibres. Two meta-analyses indicated that the components of red meat and processed meat significantly increased the risk of ESCC (Choi et al, 2013; Salehi et al, 2013). However, the present pooled result and the results from five original articles (Bahmanyar and Ye, 2006; De Stefani et al, 2008b, 2009; Navarro Silvera et al, 2011; Hajizadeh et al, 2012) showed that the association with western pattern was not statistically significant. One explanation might be that there was limited evidence on fat intake and ESCC risk (American Institute for Cancer Research and World Cancer Research Fund, 2007). Another possible explanation is that, in addition to processed meat, red meat, and fat, there was a big variation in the components contained in the western pattern. Some components even had protective roles. For instance, meat/ nitrite pattern (Navarro Silvera et al, 2011) contained vitamin C, and the meat and fat pattern (Ibiebele et al, 2012) contained poultry with skin, which were suggested to have some protective roles against ESCC (Mayne et al, 2001; Stefani et al, 2012). Moreover, the variation of other factors, such as cooking methods, grouping of animal food in different culture and studies, may be another explanation for the insignificant effect.

This systematic review was performed with an assumption of methodological homogeneity across articles in population characteristics, study design, and methods used for measuring exposure and for characterising dietary patterns. All nine included articles adopted a case-control design to explore the effects of potential dietary patterns, used FFQ to collect dietary information. In addition, the three patterns under study were selected from the included articles with similar higher factor loadings in target components. The heterogeneity of the results ranged from low to moderate in the most summarised estimates, except for that in the healthy pattern.

Body mass index was suggested to have an important role in the development of ESCC (Renehan et al, 2008; Smith et al, 2008). High caloric intake might lead to high BMI and patients with cancer might have lost weight (Wu et al, 2013). However, participants in nine articles were asked to report their weight and height at least 1 year before being diagnosed as cancer (for patients) or being interviewed (for controls), which ensured that small influence was caused by the change in weight and BMI. In addition, we need to point out that the pooled results in this present study were obtained from adjusted OR and 95\% CI, which could reduce the possible confounding effects resulting from major factors such as age, gender, and BMI.

Smoking and alcohol are two main risk factors for ESCC. People smoking are less likely to have a healthy diet (Morabia and Wynder, 1990). However, eight articles took smoking status as a confounding factor, although the categorisation of smoking status was not same, and one article (Navarro Silvera et al, 2011) took it as a component to generate a lifestyle pattern (smoking/alcohol pattern). Some problem or heterogeneity must generate when we pooled the available data. We acknowledged that people eating a western diet (such as 'Bourgondic' diet) are likely to related with high alcohol consumption. However, two articles from Iran did not take consideration of alcohol drinking when deriving dietary patterns, and seven articles from western countries took alcohol drinking as a component (Bahmanyar and Ye, 2006; De Stefani et al, 2008b, 2009; Navarro Silvera et al, 2011; Ibiebele et al, 2012) or as a confounding factor (De Stefani et al, 2008a; Bravi et al, $2012 b)$. These different ways in dealing with alcohol drinking might cause some problem or heterogeneity when we pooled the data to summarise effect size of western pattern and healthy pattern. Nevertheless, even in five articles which took alcohol drinking as a component, the factors loadings in western pattern were very low. In addition, our meta-analysis applied adjusted ORs with 95\% CI not crude ORs to generate the pooled results which might minimise this possible effect caused by smoking or alcohol drinking.

Although it is generally agreed that there is an interaction between smoking and alcohol drinking on ESCC risk (Sakata et al, 2005; Islami et al, 2011), only one article reported smoking/alcohol pattern and found significant risk effects with dose-response relationship (Navarro Silvera et al, 2011). The pooled effect of smoking-alcohol interaction on ESCC risk was not analysed because most of included articles did not explored it.

There were some limitations in this study. It is possible that more or less selection bias and recall bias might occur in some of the studies, but it is difficult to assess based on the limited information and description given in the original papers. The dietary patterns in the included articles were derived by using the principle component factor analysis, which was a subjective technique and might increase variation at almost every step (e.g., a variation in the number, type of dietary patterns derived within each study and categories of dietary patterns score) (Martinez et al, 1998; Jacques and Tucker, 2001). Although a same pattern had similarly higher factor loading of essential components, not all components in each of the patterns were identical. This could result in heterogeneity when data were pooled. In addition, only nine articles from six countries were included in this review, and the small number of articles might not be adequate to obtain conclusive evidence. Nevertheless, the current study provides useful information on dietary patterns that may be related to the risk of ESCC.

In summary, this systematic review along with meta-analysis, though based on a limited number of available studies, suggested that healthy pattern was associated with a decreased risk of ESCC, whereas drinker/alcohol pattern was related to an increased risk. This present study provides evaluations of the role of dietary patterns and ESCC risk, adding some updated information on dietary factors for ESCC that goes beyond the effects of single nutrients and foods. Although no significant association was found between western pattern and ESCC, the results from three patterns (western, healthy, and drinker/alcohol) support the current guidelines and recommendations of increasing consumption of fruits and vegetables, and reducing consumption of red and processed meat and lowering intake of alcohol for primary prevention of oesophageal cancer. The limited number of the original studies included in this meta-analysis call for the need of more numbers of carefully designed observational or intervention studies on dietary patterns and oesophageal squamous cell carcinoma.

\section{ACKNOWLEDGEMENTS}

This study was supported by World Cancer Research Fund, International (Grant No. 2010/240).

\section{CONFLICT OF INTEREST}

The authors declare no conflict of interest.

\section{REFERENCES}

American Institute for Cancer Research, World Cancer Research Fund (2007) Food, Nutrition, Physical Activity and the Prevention of Cancer: A Global Perspective: A Project of World Cancer Research Fund International. American Institute for Cancer Research: Washington, D.C. 
Bagnardi V, Rota M, Botteri E, Tramacere I, Islami F, Fedirko V, Scotti L, Jenab M, Turati F, Pasquali E, Pelucchi C, Bellocco R, Negri E, Corrao G, Rehm J, Boffetta P, La Vecchia C (2013) Light alcohol drinking and cancer: a meta-analysis. Ann Oncol 24(2): 301-308.

Bahmanyar S, Ye W (2006) Dietary patterns and risk of squamous-cell carcinoma and adenocarcinoma of the esophagus and adenocarcinoma of the gastric cardia: a population-based case-control study in Sweden. Nutr Cancer 54(2): 171-178.

Bertuccio P, Rosato V, Andreano A, Ferraroni M, Decarli A, Edefonti V, La Vecchia C (2013) Dietary patterns and gastric cancer risk: a systematic review and meta-analysis. Ann Oncol 24(6): 1450-1458.

Bosetti C, Gallus S, Trichopoulou A, Talamini R, Franceschi S, Negri E, La Vecchia C (2003) Influence of the Mediterranean diet on the risk of cancers of the upper aerodigestive tract. Cancer Epidemiol Biomarkers Prev 12(10): 1091-1094.

Bravi F, Edefonti V, Randi G, Ferraroni M, La Vecchia C, Decarli A (2012a) Dietary patterns and upper aerodigestive tract cancers: an overview and review. Ann Oncol 23(12): 3024-3039.

Bravi F, Edefonti V, Randi G, Garavello W, La Vecchia C, Ferraroni M, Talamini R, Franceschi S, Decarli A (2012b) Dietary patterns and the risk of esophageal cancer. Ann Oncol 23(3): 765-770.

Brennan SF, Cantwell MM, Cardwell CR, Velentzis LS, Woodside JV (2010) Dietary patterns and breast cancer risk: a systematic review and meta-analysis. Am J Clin Nutr 91(5): 1294-1302.

Choi Y, Song S, Song Y, Lee JE (2013) Consumption of red and processed meat and esophageal cancer risk: meta-analysis. World J Gastroenterol 19(7): 1020-1029.

De Stefani E, Boffetta P, Fagundes RB, Deneo-Pellegrini H, Ronco AL, Acosta G, Mendilaharsu M (2008a) Nutrient patterns and risk of squamous cell carcinoma of the esophagus: a factor analysis in uruguay. Anticancer Res 28(4C): 2499-2506.

De Stefani E, Boffetta P, Ronco AL, Deneo-Pellegrini H, Correa P, Acosta G, Mendilaharsu M (2008b) Exploratory factor analysis of squamous cell carcinoma of the esophagus in Uruguay. Nutr Cancer 60(2): $188-195$.

De Stefani E, Deneo-Pellegrini H, Boffetta P, Ronco AL, Aune D, Acosta G, Mendilaharsu M, Brennan P, Ferro G (2009) Dietary patterns and risk of cancer: a factor analysis in Uruguay. Int J Cancer 124(6): 1391-1397.

Dong LM, Potter JD, White E, Ulrich CM, Cardon LR, Peters U (2008) Genetic susceptibility to cancer: the role of polymorphisms in candidate genes. JAMA 299(20): 2423-2436.

Engel LS, Chow WH, Vaughan TL, Gammon MD, Risch HA, Stanford JL, Schoenberg JB, Mayne ST, Dubrow R, Rotterdam H, West AB, Blaser M, Blot WJ, Gail MH, Fraumeni Jr JF (2003) Population attributable risks of esophageal and gastric cancers. J Natl Cancer Inst 95(18): 1404-1413.

Erickson KL (2002) Dietary pattern analysis: a different approach to analyzing an old problem, cancer of the esophagus and stomach. Am J Clin Nutr 75(1): 5-7.

Freedman ND, Park Y, Subar AF, Hollenbeck AR, Leitzmann MF, Schatzkin A, Abnet CC (2007) Fruit and vegetable intake and esophageal cancer in a large prospective cohort study. Int J Cancer 121(12): 2753-2760.

Hajizadeh B, Jessri M, Akhoondan M, Moasheri SM, Rashidkhani B (2012) Nutrient patterns and risk of esophageal squamous cell carcinoma: a casecontrol study. Dis Esophagus 25(5): 442-448.

Hajizadeh B, Rashidkhani B, Rad AH, Moasheri SM, Saboori H (2010) Dietary patterns and risk of oesophageal squamous cell carcinoma: a case-control study. Public Health Nutr 13(7): 1107-1112.

Higgins J, Green S (eds) (2011) Cochrane Handbook for Systematic Reviews of Interventions, Version 5.1.0 (updated March 2011). The Cochrane Collaboration, available from http://www.cochrane-handbook.org.

Hu FB (2002) Dietary pattern analysis: a new direction in nutritional epidemiology. Curr Opin Lipidol 13(1): 3-9.

Ibiebele TI, Hughes MC, Whiteman DC, Webb PM (2012) Dietary patterns and risk of oesophageal cancers: a population-based case-control study. Br J Nutr 107(8): 1207-1216.

Islami F, Fedirko V, Tramacere I, Bagnardi V, Jenab M, Scotti L, Rota M, Corrao G, Garavello W, Schuz J, Straif K, Negri E, Boffetta P, La Vecchia C (2011) Alcohol drinking and esophageal squamous cell carcinoma with focus on light-drinkers and never-smokers: a systematic review and meta-analysis. Int J Cancer 129(10): 2473-2484.
Jacques PF, Tucker KL (2001) Are dietary patterns useful for understanding the role of diet in chronic disease? Am J Clin Nutr 73(1): 1-2.

Jemal A, Bray F, Center MM, Ferlay J, Ward E, Forman D (2011) Global cancer statistics. CA Cancer J Clin 61(2): 69-90.

Jessri M, Rashidkhani B, Hajizadeh B, Kreiger N, Bajdik CD (2011) Adherence to dietary recommendations and risk of esophageal squamous cell carcinoma: a case-control study in Iran. Ann Nutr Metab 59(2-4): 166-175.

Li JY, Taylor PR, Li B, Dawsey S, Wang GQ, Ershow AG, Guo W, Liu SF, Yang CS, Shen Q, Wang W, Mark SD, Zou XN, Greenwald P, Wu YP, Blot WJ (1993) Nutrition intervention trials in Linxian, China: multiple vitamin/mineral supplementation, cancer incidence, and disease-specific mortality among adults with esophageal dysplasia. J Natl Cancer Inst 85(18): 1492-1498.

Liu J, Wang J, Leng Y, Lv C (2013) Intake of fruit and vegetables and risk of esophageal squamous cell carcinoma: a meta-analysis of observational studies. Int J Cancer 133(2): 473-485.

Magalhaes B, Peleteiro B, Lunet N (2012) Dietary patterns and colorectal cancer: systematic review and meta-analysis. Eur J Cancer Prev 21(1): $15-23$.

Martinez ME, Marshall JR, Sechrest L (1998) Invited commentary: factor analysis and the search for objectivity. Am J Epidemiol 148(1): 17-19.

Mayne ST, Risch HA, Dubrow R, Chow WH, Gammon MD, Vaughan TL, Farrow DC, Schoenberg JB, Stanford JL, Ahsan H, West AB, Rotterdam H, Blot WJ, Fraumeni Jr JF (2001) Nutrient intake and risk of subtypes of esophageal and gastric cancer. Cancer Epidemiol Biomarkers Prev 10(10): $1055-1062$.

Morabia A, Wynder EL (1990) Dietary habits of smokers, people who never smoked, and exsmokers. Am J Clin Nutr 52(5): 933-937.

Navarro Silvera SA, Mayne ST, Risch HA, Gammon MD, Vaughan T, Chow WH, Dubin JA, Dubrow R, Schoenberg J, Stanford JL, West AB, Rotterdam H, Blot WJ (2011) Principal component analysis of dietary and lifestyle patterns in relation to risk of subtypes of esophageal and gastric cancer. Ann Epidemiol 21(7): 543-550.

Oze I, Matsuo K, Wakai K, Nagata C, Mizoue T, Tanaka K, Tsuji I, Sasazuki S, Inoue M, Tsugane S (2011) Alcohol drinking and esophageal cancer risk: an evaluation based on a systematic review of epidemiologic evidence among the Japanese population. Jpn J Clin Oncol 41(5): 677-692.

Palladino-Davis AG, Mendez BM, Fisichella PM, Davis CS (2013) Dietary habits and esophageal cancer. Dis Esophagus; e-pub ahead of print 24 June 2013; doi:10.1111/dote.12097.

Petitti DB (2000) Meta-Analysis, Decision Analysis, and Cost-Effectiveness Analysis: Methods for Quantitative Synthesis in Medicine. 2nd edn. Oxford University Press: New York; Oxford.

Qiao YL, Dawsey SM, Kamangar F, Fan JH, Abnet CC, Sun XD, Johnson LL, Gail MH, Dong ZW, Yu B, Mark SD, Taylor PR (2009) Total and cancer mortality after supplementation with vitamins and minerals: follow-up of the Linxian General Population Nutrition Intervention Trial. J Natl Cancer Inst 101(7): 507-518.

Rao M, Liu FS, Dawsey SM, Yang K, Lipkin M, Li JY, Taylor PR, Li B, Blot WJ, Wang GQ, Lewin KJ, Yu Y, Yang CS (1994) Effects of vitamin/mineral supplementation on the proliferation of esophageal squamous epithelium in Linxian, China. Cancer Epidemiol Biomarkers Prev 3(3): 277-279.

Reedy J, Wirfalt E, Flood A, Mitrou PN, Krebs-Smith SM, Kipnis V, Midthune D, Leitzmann M, Hollenbeck A, Schatzkin A, Subar AF (2010) Comparing 3 dietary pattern methods-cluster analysis, factor analysis, and index analysis-With colorectal cancer risk: The NIH-AARP Diet and Health Study. Am J Epidemiol 171(4): 479-487.

Renehan AG, Tyson M, Egger M, Heller RF, Zwahlen M (2008) Body-mass index and incidence of cancer: a systematic review and meta-analysis of prospective observational studies. Lancet 371(9612): 569-578.

Reszka E, Wasowicz W, Gromadzinska J (2006) Genetic polymorphism of xenobiotic metabolising enzymes, diet and cancer susceptibility. Br J Nutr 96(4): 609-619.

Sakata K, Hoshiyama Y, Morioka S, Hashimoto T, Takeshita T, Tamakoshi A, Grp JS (2005) Smoking, alcohol drinking and esophageal cancer: Findings from the JACC study. J Epidemiol 15: S212-S219.

Salehi M, Moradi-Lakeh M, Salehi MH, Nojomi M, Kolahdooz F (2013) Meat, fish, and esophageal cancer risk: a systematic review and dose-response meta-analysis. Nutr Rev 71(5): 257-267.

Seitz HK, Stickel F (2007) Molecular mechanisms of alcohol-mediated carcinogenesis. Nat Rev Cancer 7(8): 599-612. 
Smith M, Zhou M, Whitlock G, Yang G, Offer A, Hui G, Peto R, Huang Z, Chen Z (2008) Esophageal cancer and body mass index: results from a prospective study of 220,000 men in China and a meta-analysis of published studies. Int J Cancer 122(7): 1604-1610.

Stefani ED, Deneo-Pellegrini H, Ronco AL, Boffetta P, Correa P, Aune D, Mendilaharsu M, Acosta G, Silva C, Lando G, Luaces ME (2012) Meat consumption, cooking methods, mutagens, and risk of squamous cell carcinoma of the esophagus: a case-control study in Uruguay. Nutr Cancer 64(2): 294-299.

Steinmetz KA, Potter JD (1991) Vegetables, fruit, and cancer. II. Mechanisms. Cancer Causes Control 2(6): 427-442.

Sterne JAC, Egger M (2001) Funnel plots for detecting bias in meta-analysis: guidelines on choice of axis. J Clin Epidemiol 54(10): 1046-1055.

Stroup DF, Berlin JA, Morton SC, Olkin I, Williamson GD, Rennie D, Moher D, Becker BJ, Sipe TA, Thacker SB (2000) Meta-analysis of observational studies in epidemiology: a proposal for reporting. Meta-analysis Of Observational Studies in Epidemiology (MOOSE) group. JAMA 283(15): 2008-2012.

Terry P, Lagergren J, Ye W, Nyren O, Wolk A (2000) Antioxidants and cancers of the esophagus and gastric cardia. Int J Cancer 87(5): 750-754

Toh Y, Oki E, Ohgaki K, Sakamoto Y, Ito S, Egashira A, Saeki H, Kakeji Y, Morita M, Sakaguchi Y, Okamura T, Maehara Y (2010) Alcohol drinking, cigarette smoking, and the development of squamous cell carcinoma of the esophagus: molecular mechanisms of carcinogenesis. Int J Clin Oncol 15(2): 135-144.

\section{APPENDIX 1}

\begin{tabular}{|c|c|c|c|}
\hline & PubMed/Embase search & CNKI/VJIP search & Where treated \\
\hline & (English database) & (Chinese database) & \\
\hline 1 & Oesophageal cancer & 食管癌 & Title/abstract \\
\hline 2 & $\begin{array}{l}\text { Oesophageal squamous cell } \\
\text { carcinoma }\end{array}$ & 食管鳞癌 & Title/abstract \\
\hline 3 & Oesophageal neoplasm & 食管肿瘤 & Title/abstract \\
\hline 4 & Dietary pattern & 膳食模式/结构 & Title/abstract \\
\hline 5 & Nutrients pattern & 营养素模式/结构 & Title/abstract \\
\hline 6 & Food pattern & 食物模式/结构 & Title/abstract \\
\hline 7 & Eating pattern & 饮食模式/结构 & Title/abstract \\
\hline 8 & Dietary habits & 饮食习惯 & Title/abstract \\
\hline 9 & Diet & 膳食 & Title/abstract \\
\hline 10 & Dietary & 膳食 & Title/abstract \\
\hline 11 & Nutrients & 营养素 & Title/abstract \\
\hline 12 & \multicolumn{3}{|l|}{1 OR 2 OR 3} \\
\hline 13 & \multicolumn{3}{|c|}{4 OR 5 OR 6 OR 7 OR 8 OR 9 OR 10 OR 11} \\
\hline 14 & \multicolumn{3}{|l|}{12 and 13} \\
\hline 15 & \multicolumn{3}{|c|}{ Limited to English or Chinese language } \\
\hline 16 & \multicolumn{3}{|l|}{ Limited to humans study } \\
\hline 17 & \multicolumn{3}{|c|}{$\begin{array}{l}\text { Limited to factor analysis/principle component factor analysis/ } \\
\text { cluster analysis }\end{array}$} \\
\hline 18 & \multicolumn{3}{|c|}{ Limited 14 to (15 and 16 and 17$)$} \\
\hline
\end{tabular}

Wells G, Shea B, O'Connell D, Peterson J, Welch V, Losos M, Tugwell P (2011) The Newcastle-Ottawa Scale (NOS) for assessing the quality of nonrandomised studies in meta-analyses www.ohri.ca/programs/ clinical_epidemiology/oxford.htm.

Wright ME, Virtamo J, Hartman AM, Pietinen P, Edwards BK, Taylor PR, Huttunen JK, Albanes D (2007) Effects of alpha-tocopherol and beta-carotene supplementation on upper aerodigestive tract cancers in a large, randomized controlled trial. Cancer 109(5): 891-898.

Wu J, Huang CH, Xiao HB, Tang QY, Cai W (2013) Weight loss and resting energy expenditure in male patients with newly diagnosed esophageal cancer. Nutrition 29(11-12): 1310-1314.

Wu M, Zhang ZF, Kampman E, Zhou JY, Han RQ, Yang J, Zhang XF, Gu XP, Liu AM, van't Veer P, Kok FJ, Zhao JK (2011) Does family history of cancer modify the effects of lifestyle risk factors on esophageal cancer? A population-based case-control study in China. Int J Cancer 128(9): $2147-2157$.

Yusof AS, Isa ZM, Shah SA (2012) Dietary patterns and risk of colorectal cancer: a systematic review of cohort studies (2000-2011). Asian Pac J Cancer Prev 13(9): 4713-4717.

This work is published under the standard license to publish agreement. After 12 months the work will become freely available and the license terms will switch to a Creative Commons AttributionNonCommercial-Share Alike 3.0 Unported License. 


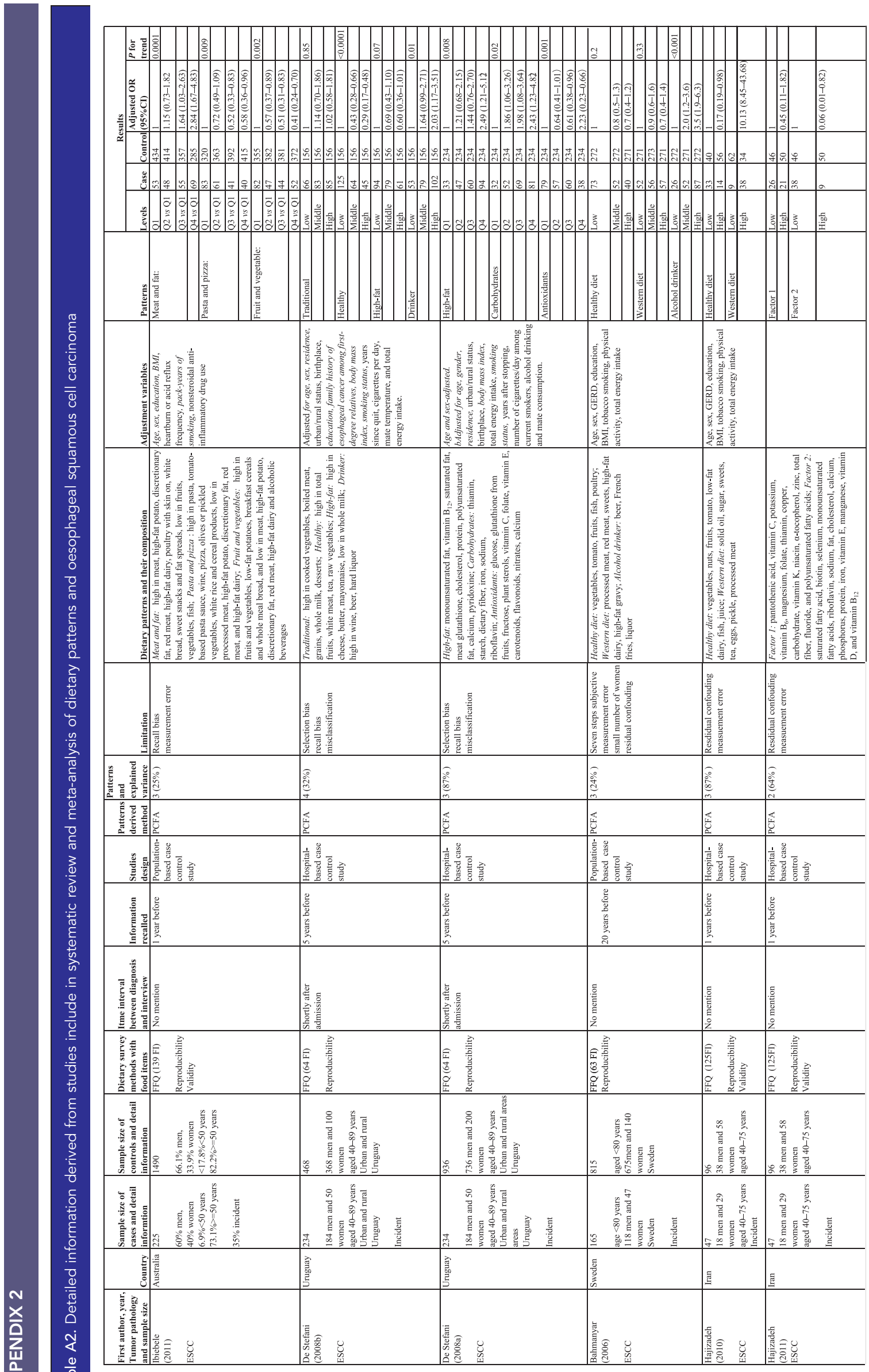




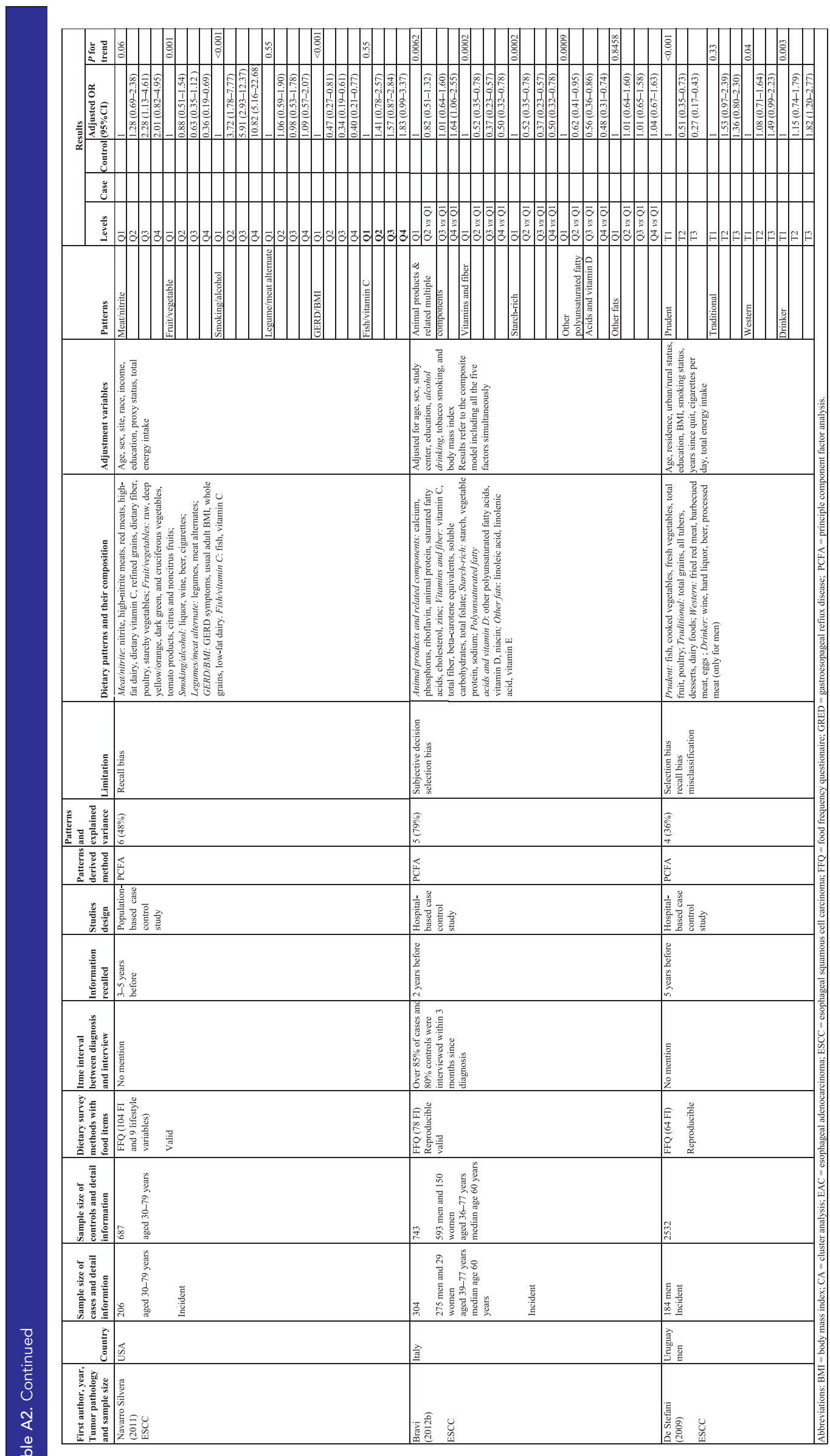




\section{APPENDIX 3}

Table A3. Quality assessment of included studies on dietary pattern and risk of oesophageal squamous cell carcinoma

\begin{tabular}{|l|c|c|c|c|c|}
\hline Articles, Year & Selection & Comparability & Exposure & Overall & Grade \\
\hline $\begin{array}{l}\text { Ibiebele } \text { et al, } \\
2012\end{array}$ & 4 & 2 & 1 & 7 & High \\
\hline $\begin{array}{l}\text { Bahmanyar } \\
\text { and Ye, 2006 }\end{array}$ & 4 & 2 & 2 & 8 & High \\
\hline $\begin{array}{l}\text { De Stefani } \\
\text { et al, 2008a }\end{array}$ & 3 & 2 & 3 & 8 & High \\
\hline $\begin{array}{l}\text { De Stefani } \\
\text { et al, 2008b }\end{array}$ & 3 & 2 & 3 & 8 & High \\
\hline $\begin{array}{l}\text { Hajizadeh } \\
\text { et al, 2010 }\end{array}$ & 3 & 2 & 2 & 7 & High \\
\hline $\begin{array}{l}\text { Hajizadeh } \\
\text { et al, 2012 }\end{array}$ & 3 & 2 & 2 & 7 & High \\
\hline $\begin{array}{l}\text { Bravi } \text { et al, } \\
\text { 2012b }\end{array}$ & 3 & 2 & 3 & 8 & High \\
\hline $\begin{array}{l}\text { Navarro } \\
\text { Silvera } \text { et al, } \\
\text { 2011 }\end{array}$ & 3 & 2 & 2 & 7 & High \\
\hline $\begin{array}{l}\text { De Stefani } \\
\text { et al, 2009 }\end{array}$ & 3 & 2 & 3 & 8 & High \\
\hline
\end{tabular}

(i) The study quality was assessed according to the Newcastle Ottawa Quality assessment scale for case-control studies. (ii) The scale awards a maximum of 9 points to each study: 4 for selection, 2 for comparability, and 3 for assessment of exposures. (iii) Comparability was assessed based on the adjustment of age, sex, body mass index, smoking status, and education. (iv) Response-rate difference less than $10 \%$ was considered as same response rate for both groups. (v) Grade was classified as low (overall quality score ranged from 1 to 3), median (4-6), and high (7-9). 